\title{
PEMURIDAN MODEL EPAFRAS SEBAGAI UPAYA PENDEWASAAN IMAN BAGI WARGA GEREJA
}

\author{
Sostenis Nggebu \\ Sekolab Tinggi Teologi Saint Paul \\ Jl. Purbasari No. 3, Sangkuriang, Cimabi 40511, Jawa Barat \\ Email:sostenis.nggebu@gmail.com
}

\begin{abstract}
ABSTRAK: Tinjauan artikel ini membahas pemuridan sebagai implementasi dari Amanat Agung untuk mendewasakan warga gereja menjadi serupa dengan Yesus Kristus. Untuk maksud itu penulis membahas konsep pemuridan yang dikerjakan oleh Epafras bagi jemaat Kolose. Dalam teks Kolose 1:3-11, Epafras memuridkan orang-orang Kristen Kolose agar memiliki karakter Kristus sekaligus memperlengkapi mereka ambil bagian sebagai pekerja Kristus (Kol. 1:28, 29). Dengan menggunakan metode deskriptif analitik, penulis berusaha menjelaskan pemuridan yang digunakan oleh Epafras. Dari studi ini tampak bahwa Epafras memuridkan orang-orang Kristen Kolose supaya mereka memiliki kedewasaan rohani dalam Kristus; memperlengkapi mereka untuk melanjutkan tugas pemuridan tersebut; juga mereka memiliki pemahaman yang benar tentang kehidupan dalam Kristus untuk menangkal ajaranajaran palsu yang merebak di tengah jemaat. Dengan demikian, maka umat Kristen Kolose dapat berdiri teguh dalam iman mereka kepada Tuhan Yesus Kristus.
\end{abstract}

Kata kunci: epafras; injil; pemuridan; pekerja; kolose

\section{THE MODEL OF EPAPHRAS DISCIPLESHIP AS AN EFFORT OF MATURING CHURCH MEMBERS' FAITH}

\begin{abstract}
This article discusses the study of Christian discipleship as the implementation of the Great Commission to mature the church members becoming conformed to Jesus Christ. For that purpose, the author discusses the concept of discipleship done by Epaphras for the Colossians. In Colossians 1:3-11, Epaphras discipled the Colossians so that they possess the character of Christ. He also equipped them to take part as the laborers of Christ (Col. 1:28, 29). Utilizing descriptive-analytical methods, the author concludes that Epaphras discipled the Colossian Christians to have spiritual maturity in Christ; equip them to continue the task of discipleship; also, they have a correct understanding of life in Christ to protect the Colossians from false teachings spread among the church. Thus, Colossian Christians can stand firm in their faith in the Lord Jesus Christ.
\end{abstract}

Keywords: epaphras; gospel; discipleship; workers; colossians 


\section{PENDAHULUAN}

Wasiat akhir Yesus disebut Amanat Agung. Karena hakikat amanat itu sanggup mentransformasikan manusia menjadi pribadi baru. Di situlah pentingnya kiprah gereja memanggil orang-orang berdosa agar diperdamaikan dengan Yesus Kristus. Dalam konteks itu Heath mengatakan misi Paulus dalam rangka melaksanakan Amanat Agung Yesus agar orang berdosa dituntun kepada Yesus (Heath, 2016, p. 63-71). Hull dan Sobels menegaskan Injil telah mengubah dunia sejak diberitakan oleh para pemimpin gereja pada abad pertama Masehi (Hull, 2017, p. 24 ). Jelas sekali bahwa Yesus sebagai pusat Injil dan ada banyak hal yang menakjubkan yang dikatakan tentang Yesus (Treneer, 2012, p. 24). Beberapa jurnal teologi dan misi membahas pentingnya pemuridan dan Amanat Agung. Purnawan Tenibemas, misalnya, mengatakan andil gereja dalam misi bersumber dari Amanat Agung Yesus yang tertuang dalam Matius 28:19-20 (Tenibemas, 2019, p. 23). Analisis yang sama dikemukakan oleh Patrecia Hutagalung bahwa mandat misi bersumber dari Amanat Agung Matius 28:18-20 (Hutagalung, 2020, p. 64-76). Pandangan para peneliti menunjukkan bahwa pelaksanaan Amanat Agung penting sebagai landasan teologis bagi pembinaan iman warga gereja. Untuk itu kajian ini bertujuan menjelaskan tentang bagaimana pola pemuridan yang digunakan oleh Epafras dalam rangka mendewasakan iman jemaat Kolose. Sebagai acuan pembahasannya maka penulis memaparkan model pemuridan Epafras yang bersumber dari Kolose 1:3-11. Tulisan ini fokus pada bagaimana model pemuridan yang dilakukan oleh Epafras? Bagaimana implikasinya bagi gereja masa kini?

\section{METODE}

Penulisan artikel ini menggunakan metode deskriptif dan analitik. Menurut Winarno Surakhman, penelitian yang bersifat deskriftif dimaksud untuk menjelaskan dan menafsirkan data yang berkaitan dengan topik kajian; dan juga bersifat analitik karena data yang dikumpulkan akan dikaji, dianalisis, dijelaskan dan dirumuskan hasilnya (Surakhman, 1998, 139-140). Analisis juga berarti suatu usaha untuk mencari bagian-bagian yang menjadi komponen utama dari data yang dihimpun (biasanya masih bersifat luas), kemudian disusun dalam suatu bentuk kerangka pengertian yang terfokus pada subjek penelitian yakni berkaitan dengan masalah pemuridan oleh Epafras bagi jemaat Kolose.

Data mengenai pemuridan diperoleh dari studi literatur (kepustakaan), terutama Alkitab. Namun supaya penulisan ini bersifat ilmiah (objektif) maka penulis menggunakan juga studi literatur atau karya tulis ilmiah lainnya (termasuk artikel jurnal atau e-book dari internet) yang membahas tentang pemuridan. Untuk melengkapi hasil penelitian ini, maka penulis juga memanfaatkan buku tafsiran Alkitab (berkaitan dengan surat Kolose), kamus teologi dan ensiklopedia Alkitab.

Prosedur penelitian ini ditempuh dengan mengumpulkan semua dokumen yang dibutuhkan, kemudian dibaca, disimak, ditanggapi, dikritisi, dianalisis dan membuat sistematika pemikiran serta mengurai data tersebut dalam tubuh karya tulis ini. Dengan demikian, hasil akhirnya dapat membentuk wawasan teologis berkenaan dengan konsep pemuridan dalam surat Kolose, yakni pemuridan model Epafras guna mendewasakan iman warga gereja.

\section{HASIL DAN PEMBAHASAN}

\section{Konteks surat Kolose}

Surat Kolose merupakan buah pena rasul Paulus. Michael F. Bird meyakini surat Kolose ditulis oleh Rasul Paulus ketika beliau dipenjarakan di Roma pada tahun 60-62 M. Pandangan itu dapat dilihat dari gaya dan isi surat Kolose. Selain itu konsep peninggian Kristologi cocok dengan surat-surat lain yang ditulis oleh rasul Paulus (Bird, 2009, p. 3-9). 
Dari segi karakter, surat ini menjabarkan beberapa sosok yang merupakan rekan sekerja Paulus, seperti Tikhikus, saudara yang kekasih, hamba yang setia dan kawan pelayanan dalam Tuhan (4:7). Onesimus, saudara kita yang setia dan yang kekasih, seorang dari antaramu (4:8). Aristakhus, teman sepenjara (4:10); dan Yustus dan Markus juga sebagai orang-orang berkaitan dengan pelayanan sang rasul sendiri. Charles Talbert memiliki pandangan yang sama, surat Kolose ditulis oleh Paulus bersamaan dengan surat Efesus (Ef. 3:1; 4:1; 6:20; Kol. 4:3, 10, 18). Tikhikuslah yang membawa surat ini kepada jemaat Kolose dan Efesus (Ef. 6:21-22; Kol. 4:7-9). Beliau yakin kedua isi surat ini memiliki kesamaan. Dalam Efesus 1:1-2 sama dengan Kolose 1:1-2; demikian juga Efesus 6:21-22 identik dengan Kolose 4:7-8 (Talbert, 2007, p. 3-4).

Dari sudut topografi, kota Kolose terletak di daerah Prigia, provinsi Romawi Barat, tepatnya di sebelah barat daya Turki. Di sana terdapat pelabuhan di tepi sungai yang ramai didatangi para pedagang. Kota ini juga terkenal sebagai pusat perdagangan wol hitam lembut yang diburu oleh para pedagang dari berbagai negeri. Daerah perbukitan kota menjadi padang penggembalaan ternak penghasil wol. Kota ini termasuk berkembang dari segi ekonomi sehingga mudah dijumpai berbagai komunitas masyarakat yang menetap di sana (Tenney, 1992, p. 396-402).

Masalah keagamaan juga menonjol di Kolose. Sebagai kota yang terletak pada jalur perniagaan, Kolose memunculkan beragam agama dan guru-guru palsu yang mengajarkan tentang kepenuhan ramai dicari di sana seperti bertapa (2:8, 20-21) dan beribadah kepada malaikat (2:18), berpantang makanan tertentu (2:16), pertapaan atau asketisme $(2: 16,21)$. Kelihatannya masalah "kepenuhan" pengetahuan yang batiniah dicari mereka. Lebih parah lagi, semuanya itu dianggap bagian dari Injil. Karena itu, Paulus mengupayakan suatu pemahaman tentang pentingnya kehidupan yang didasarkan atas kepenuhan dalam Tuhan. Paulus merasa terpanggil untuk mengingatkan rekan-rekannya di sana agar bekerja dalam kasih sebagai salah satu cara membendung ajaran-ajaran sesat yang marak menarik jemaat keluar dari lingkungan persekutuan gereja (Wiersbe, 2001, p. 30-38).

Jemaat Kristen di Kolose berkembang pesat melalui pemuridan. Tetapi untuk menunaikan amanat pemuridan tersebut mereka membayar harga yang mahal mengingat mereka berhadapan dengan tantangan baik dari dalam maupun luar jemaat. Drane menganggap mereka berhadapan dengan masalah pelik secara interen. Masalah "ajaran palsu Kolose” (Drane, 2006, p. 380-381). Di dalam jemaat Kolose terdapat sejumlah kalangan yang menganggap diri mereka lebih baik dari pada orang lain. Mereka dipengaruhi oleh guru agama Yahudi yang menganut ajaran bidatbidat kafir yang berkembang pesat di Kolose sama seperti di daerah-daerah lain. Mereka menganut paham bahwa keselamatan dalam Yesus tidak lengkap jika tidak ditambah dengan pengertian yang bersifat ilahi melalui pengetahuan rahasia yang diperoleh secara mistik (Kol 3:23). Mereka dipengaruhi oleh ajaran gnostik yang merajalela juga di Korintus. Pengetahuan itu didapat dengan mengambil bagin dalam berbagai praktik upacara agama seperti sunat, pantang makan makanan tertentu, dan memelihara hari-hari raya Yahudi dan Sabat (Drane, 2006, p. 381). Dengan menyimak konteks yang dihadapi oleh jemaat Kristen di Kolose, maka pembinaan iman yang dewasa dalam Kristus menjadi kebutuhan yang mendesak.

\section{Analisis teks Kolose 1:3-11}

Kolose 1:3-13 mengungkapkan implementasi pemuridan yang dilakukan oleh Epafras. Di sini terlihat bahwa orang-orang Kolose yang diinjili itu ditindaklanjuti dengan memuridkan mereka. Dalam 1:7, Paulus memaparkan fakta bahwa orang-orang Kolose 
itu telah "tahu" tentang Injil dari Epafras dan pengaruh dari kuasa Injil itu telah bekerja secara kuat di dalam hidup mereka (1:29-29). Paulus juga menjelaskan bahwa Epafras "lebih dahulu" (1:5) mengajar mereka sebelum munculnya guru-guru palsu. Dengan demikian terlihat bahwa peran Epafras dalam pendidikan iman warga gereja di Kolose mengikuti prinsip pendidikan yang telah maju pada zaman gereja mula-mula. Beliau telah menanamkan kebenaran Injil bagi warga gereja di Kolose sebagai pencapaian maksimal dari pemahaman akan kebenaran. Sehingga, hasilnya orang-orang Kristen Kolose menjadi orang yang setia dalam iman kepada Yesus Kristus (1:6, 8); memiliki kasih yang hidup di antara mereka (1:4); bahwa kasih itu telah mempersatukan mereka dalam gereja (2:2); dan hidup dalam pengharapan (1:5). Paulus juga menjabarkan bahwa Epafras setia mendoakan mereka $(1: 9,10)$ supaya mereka tetap memiliki moral yang sehat dalam Tuhan Yesus Kristus (1:11-13).

Dalam Bible Works 10, kata "tahu" dalam Kolose 1:7 berasal dari kata Yunani $\dot{\varepsilon} \mu \dot{\alpha} \theta \varepsilon \tau \varepsilon$ sebagai kata kerja indikatif aorist aktif orang kedua jamak dari kata $\mu \alpha \nu \theta \dot{\alpha} \nu \theta \dot{\alpha}$ ( $\varepsilon_{\mu \alpha \theta o v)}$ yang berarti: belajar, mempelajari, mengetahui atau belajar di sekolah rabi. Seperti dikatakan dalam Yohanes 7:15, "Maka heranlah orang-orang Yahudi dan berkata: 'Bagaimanakah orang ini mempunyai pengetahuan demikian tanpa belajar!”' Proses belajar di sini diartikan melalui penyelidikan atau mendengar materi ajar dari guru atau juga mungkin belajar memahami sendiri.

Charles Talbert dalam bukunya Ephesians and Colossians (Talbert, 2007, p. 175) telah menjabarkan lebih jauh apa yang dikemukakan dalam Bible Works 10. Talbert memaparkan makna dari konsep belajar yang mengarahkan pikiran seseorang guna menghasilkan efek eksternal yakni:

1. Pembelajaran melalui instruksi yang diajarkan, belajar dari guru agar murid mengingat apa artinya pertobatan (bdk. Ef. 6:1). Pendekatan ini bertujuan untuk menolong murid mengingat makna pertobatan mereka $(1: 12-14 ; 21-22 ; 2: 10$, 11-15, 20a; 3:1a, 3).

2. Pembelajaran melalui inkuiri memastikan, menemukan, mencari tahu sendiri (bdk. Kis. 23:27). Guru membuat murid aktif dalam belajar sehingga ia mengingat ajaran yang sedang berlangsung dikaitkan dengan awal pertobatannya. Bagian ini merupakan kunci dari pokok-pokok pengajaran doktrin di Kolose (1:15-20; 2:9).

3. Proses belajar melalui praktik atau pengalaman menjadi tahu, yang menuntun murid menjadi sadar (bdk. Flp. 4:11; Ibr. 5:8). Di sini guru memfasilitasi murid mengarahkan pikirannya untuk aktif belajar (1:6-7; 1:24-2:5; 4:7-9).

4. Pencapaian pemahaman atau belajar memahami (bdk. Why 14:3). Dalam bagian ini seorang murid diharapkan mengingat pengalaman dan kemajuan belajar hingga sekarang (3:9b-10a; 3:5-9a dan 3:10b-17).

Teknik belajar sebagaimana dikemukakan dalam Bible Work 10 dan juga dalam penjabaran Talbert mengindikasikan Paulus memahami bahwa teknik belajar ini telah dipraktikkan oleh Epafras di Kolose sehingga warga gereja di Lembah Likhus itu dapat memahami arti Kekristenan dan memiliki wawasan teologis yang Injili (Talbert, 2007, p. 178). Kelihatannya dalam filsafat moral dikombinasikan antara ajaran dan doktrin sehingga saling melengkapi yang mengarahkan seorang murid memahami kebenaran yang sahih. Tujuan yang hendak dicapai yakni (1) membimbing seorang ke arah perilaku yang benar yakni moralitas Kristen; (2) bertujuan untuk membasmi ajaran yang salah (bidat). Karena itu diperlukan doktrin yang benar dalam pemuridan (3:1-2; $15-17$ dan 3:8-4:6). 
Bahwa moral yang benar bersumber dari ajaran/doktrin yang benar pula (3:1; 3-4).

Sekalipun metode pengajaran tersebut di atas masih bersifat mentransfer pengetahuan dari guru kepada murid sebagaimana kebiasaan para pendidik Yunani kuno, tetapi memiliki manfaat besar sesuai nuansa strategi pendidikan masa itu. Rupanya, Epafras telah menggunakan proses filosofis untuk mendidik orang-orang Kolose dalam doktrin Kristologi yang membuat mereka bertumbuh menjadi dewasa dalam iman kepada Yesus Kristus. Epafras telah berkontribusi besar dalam pemberitaan Injil yang mengubahkan hidup warga gereja di Kolose sehingga mampu mengerti dan menghayati secara mendalam hakikat iman Kristen yakni hidup dalam kepenuhan Kristus.

\section{Citra Epafras}

Pada pertengahan abad pertama Masehi sudah berdiri jemaat Kristen di Kolose. Jemaat itu bukan hasil langsung dari pemberitaan Paulus. Epafraslah perintis gereja di Kolose. Salah satu indikasinya, Epafras bertobat semasa Rasul Paulus melayani di Efesus (Kis. 19:10) lalu dimuridkan dan kemudian diutus ke Kolose. Treneer menganggap mereka sebagai cucu atau cicit rohani dari Rasul Paulus (Treneer, 2012, p. 34). Dalam penelitiannya, Talbert memberi argumentasi yang logis, bahwa gereja di Kolose didirikan oleh Epafras (Kol. 1: 6-7), seorang pribumi dari Kolose (4:12) dan sebagai utusan Rasul Paulus (1:8). Paulus secara pribadi tidak diketahui oleh mayoritas orang Kristen di Lembah Likhus (2:1). Dia tampaknya tahu tentang jemaatjemaat di sana dari Filemon dan Nympha.

Gereja di Kolose rupanya terletak di rumah Filemon (Flm. 1-2). Asumsinya bahwa Filemon berada di Kolose karena konon Onesimus sebagai salah satu dari orang Kristen Kolose (Kol 4:9, "salah satu dari kamu”). Di mana letak gereja rumah Nympha tidak jelas. Sepertinya tidak cocok baik di
Kolose atau di Laodikia (4:15). Apakah ini mengarah ke Hierapolis? (Talbert, 2007, p. 178). Jemaat di Kolose tampaknya berada dalam keadaan baik (Kol. 1:8, 23; 2:5), jika dalam keadaan bahaya sekalipun mereka tetap setia dalam imannya (2:8). Menurut Gerald F. Hawthorne baik Kolose, Hierapolis dan Laodikia merupakan daerah pemukiman yang terletak di Lembah Likhus itu sendiri (Hawthorne, 1993, p. 147). Weirsbe membenarkan argumen tersebut di atas bahwa Epafras selain merintis gereja di Kolose, ia juga mempunyai pelayanan di Hierapolis dan Laodikia (Kol. 4:12,13 [Wiersbe, 2001, p. 910]). Kolose berjarak sekitar 12 mil dari Laodikia. Secara logis dapat dipahami bahwa peranan Epafras sebagai seorang gembala yang aktif dalam pemberitaan Injil dan pemuridan yang berdampak di kota-kota kecil yang maju di Lembah Likhus tersebut.

Epafras merupakan seorang pekerja yang dikasihi oleh Paulus (ay. 7a). Paulus menganggapnya sebagai seorang rekan sekerja dalam pemberitaan Injil (ay. 7b); memiliki nama baik di mata jemaat dan para pemimpin gereja mula-mula; dan memenuhi kriteria sebagai orang yang setia melayani pekerjaan Tuhan. Artinya, ia memiliki keunikan khusus sebagai seorang pembimbing rohani. Kata Yunani pistos (faithful) dipakai dalam ayat ini untuk menggambarkan citra Epafras. Istilah pistos dalam ayat ini mempunyai dua bentuk: (a) pasif (to be trusted, reliable), yakni sebagai orang yang dapat dipercayai atau dapat diandalkan. (b) aktif (believing, trusting, relying), yakni orang yang penuh kepercayaan atau orang yang menyandarkan hidupnya kepada Tuhan (Nggebu, 2011, p. 151).

Seorang pekerja Kristus yang dapat dipercayai dan dapat diandalkan melekat kuat dalam diri Epafras. Kesetiaannya pun teruji sebagai seorang hamba Kristus. Hamba di sini diartikan sebagai "budak" (doulos) Kristus. Posisi Epafras sebagai milik Kristus, yang meng-hamba-kan dirinya bagi kepentingan 
Kristus. Epafras seorang pemberita Injil dan pembimbing yang mendewasakan warga gereja di Kolose. Kekhasan Epafras adalah menghidupi pelayanan pemuridan sebagai jantung dari keberadaan gereja dan pembangunan rohani warga gereja. Paulus mengatakan "ia seorang dari antaramu, hamba Kristus Yesus, yang selalu bergumul dalam doanya untuk kamu, supaya kamu berdiri teguh, sebagai orang-orang yang dewasa dan yang berkeyakinan penuh dengan segala hal yang dikehendaki Allah" (Kol. 4:12). Penilaian mentornya itu memiliki alasan. Epafras seorang model dalam implementasi konsep pemuridan demi kemajuan rohani warga gereja di Kolose.

Pada saat surat Kolose ditulis, jemaat Kolose sudah berdiri sekitar 15 tahun sebelumnya. Dan dalam periode itu, jemaat Kolose telah berkembang pesat. Juga selama masa itu, Epafras telah menginjili dan memuridkan banyak warga gereja di Lembah Likhus, baik yang menetap di Kolose, Hierapolis dan Laodikia. Dalam kunjungannya ke Roma untuk menemui Paulus, dan melaporkan tentang bahaya bidat yang mengancam umat Allah di Kolose, Epafras malah memutuskan tinggal bersama Paulus di penjara di Roma (bdk. Flm 23). Menarik bahwa ia bukan pelanggar hukum. Tetapi atas dasar sukarela melepaskan kenyamanan pribadinya agar dapat menemani sang rasul menjalani hukumannya di penjara (Wiersbe, 2001, p. 12). Agaknya bagi Epafras para pekerja yang telah dimuridkannya di Kolose memiliki kapasitas yang sama dengan dirinya untuk melanjutkan karya misi yang telah diletakkannya. Dalam suratnya kepada jemaat Kolose, Paulus mengingatkan orang-orang Kristen di Lembah Likhus itu agar tetap setia kepada Yesus Kristus, berpegang tehuh pada kebenaran yang telah diajarkan kepada mereka oleh Epafras sehingga iman mereka tetap terpelihara.

\section{Wawasan Pemuridan Epafras Terbentuk di Efesus}

Perjumpaan antara Paulus dengan Epafras terjadi di Efesus. Sebagaimana dilaporkan dalam Kisah Para Rasul 19:10, tentang buah-buah pertobatan dari pelayanan Paulus selama tiga tahun di kota Efesus, termasuk Epafras. Ia telah percaya kepada Tuhan Yesus dan menerima pengampunan dan hidup baru. Menurut Heath kalau seseorang percaya kepada Yesus, dengan kesadaran demikian-ia tahu dengan jelas bahwa keselamatan Kristen ialah terutama masalah rohani-yaitu pengampunan dosa dan keselamatan surgawi (Heath, 2016, p. 158).

Pembinaan rohani yang dialaminya dari Paulus telah membuka wawasannya untuk meneruskan konsep pemuridan ke negeri asalnya. Itu berarti Injil telah mengubah cara pandangnya. Berita keselamatan tentang Kristus sang Penyelamat bukan hanya bagi bangsa Israel tetapi milik bangsa-bangsa lain juga. Injil patut diberitakan bagi semua orang. Hull mengemukakan pandangannya bahwa para pemimpin gereja abad pertama mengkhotbahkan Injil dengan sangat jelas bagi para pendengarnya, maka kuasa Injil itu bekerja secara hebat. Injil Yesus Kristus mulai mengubah dunia (Hull, 2017, p. 24). Tatanan baru terbentuk di tengah masyarakat. Orang banyak menganut moralitas Kristen yang membarui masyarakat secara luas. Tenibemas mengatakan bahwa peran serta orang percaya dalam misi untuk menyampaikan berita pertobatan dan pengampunan dosa dalam Yesus Kristus bagi segala bangsa (Tenibemas, 2019, p. 35). Injil itu bagaikan dinamit yang berkuasa menghancurkan penghalang yang menyelubungi kehidupan manusia. Sehingga, orang-orang yang mendengar Injil itu rela bertobat dan menyerahkan hidup mereka kepada Yesus Kristus. Mereka bukan hanya percaya tetapi menghidupi makna Injil. Hull percaya jika Injil diberitakan dengan jelas maka kuasa Injil itu akan bekerja mengubah hati 
manusia (Hull, 2017, p. 25). Orang-orang menerima Injil melalui pemberitaan Epafras itu mengalami pembaruan sebelum mereka diperlengkapi ke arah pemuridan.

\section{Hakikat dan Makna Pemuridan}

Menarik bahwa Epafras tidak hanya membawa orang-orang Kolose kepada Kristus lalu meninggalkan mereka. Epafras memutuskan untuk mengajar mereka firman Tuhan dan berusaha meneguhkan iman mereka (Wiersbe, 2001, p. 24, 25). Peneguhan dan pemuridan sebagai dua istilah yang penting dalam pembangunan kerohanian warga gereja pada era gereja mula-mula.

Dalam pandangan Heath, peneguhan berarti memberikan keyakinan bahwa orang yang percaya kepada Yesus itu telah memiliki kepastian selamat (Heath, n.d. p. 59). Setelah seseorang berdoa untuk percaya kepada Yesus, jelaskanlah jalan keselamatan itu sekali lagi, dan tuntunlah ia berdoa untuk kedua kalinya. Diharapkan bahwa melalui peneguhan ia diyakinkan tentang kedudukannya sebagai anak-anak Allah yang telah memiliki kepastian keselamatan pribadi (Heath, n.d. p. 60). Rasul Yohanes mengatakan, "Siapa memiliki Anak ia memiliki hidup; siapa tidak memiliki Anak, ia tidak memiliki hidup. Semuanya itu kutuliskan kepada kamu, supaya kamu yang percaya kepada nama Anak Allah, tahu, bahwa kamu memiliki hidup yang kekal" (1 Yoh. 5:12,13). Orang yang sudah percaya memerlukan pemeriksaan kembali dasar keyakinan mereka. Hal ini bertujuan agar keyakinan mereka terhadap Yesus Kristus semakin kokoh dan mantap untuk siap dimuridkan demi pertumbuhan iman mereka menjadi dewasa.

Pola pembinaan iman yang terstruktur telah dipopulerkan dalam konteks gereja mulamula. Johnson mengatakan bahwa dalam konteks abad-abad pertama, masyarakat sudah mengenal struktur tententu yang dapat dikembangkan menjadi media pembelajaran yang mempunyai ciri-ciri seperti tatap muka, membaca, menulis, praktik dan mengikuti ujian sebagai simbol yang disebut pendidikan (Johnson, 2012, p. 18). Dengan demikian dapat dimengerti bahwa pemuridan atau pemerlengkapan terhadap Epafras telah mengikuti juga simbol pendidikan di atas, yang membuat dirinya semakin tajam dalam pemahaman teologi dan praktika. Dia pun sudah ditawan ke dalam konsep pembangunan iman warga gereja agar menjadi serupa dengan Kristus. Wiersbe mengatakan pandangannya yang sama. Pada zaman itu, seorang murid tidak hanya duduk dan mendengar pengajaran guru. Ia hidup bersama gurunya dan belajar dengan mendengar, mengamati dan melakukan. Pemuridan lebih dari sekadar mendaftarkan diri di sebuah sekolah dan mengikuti kuliah. Pemuridan berarti penyerahan diri penuh kepada sang guru. Artinya belajar dengan melakukan (Wiersbe, 2001, p. 25). Hal ini senada dengan pandangan Yuliati dan Yermima, bahwa pemuridan mengarah pada hubungan interdependensi antara pemimpin dan orang yang dilayani yakni saling bergantung, saling menguatkan, saling bertumbuh dalam iman menjadi serupa dengan Yesus (Yuliati \& Yemima, 2019, p. 37).

Pembinaan warga gereja biasanya berkaitan dengan peneguhan dan pemuridan. Di sini muncul dua hal yakni mengajar (pemuridan) dan peneguhan. Greg Odger mengatakan pemuridan adalah membangun hubungan yang disengaja sebagai tempat guru atau pembimbing berjalan bersama murid lain untuk mendorong, melengkapi dan menantang satu sama lain dalam kasih untuk bertumbuh menuju kedewasaan dalam Kristus. Ini termasuk memperlengkapi murid tersebut untuk mengajar orang lain juga agar mereka melakukan hal yang sama (Ogden, 2007, p. 17). Pemuridan berkaitan erat antara menanamkan nilai-nilai kebenaran agar murid itu berjalan bersama Yesus dan sekaligus memperlengkapinya untuk melakukan pemuridan bagi generasi berikutnya. Edmund Chan 
mendefinisikan arti pemuridan yang serupa. Pemuridan sebagai proses belajar bersamasama para murid, mendewasakan iman mereka, dan mengambil bagian dalam menghasilkan generasi rohani berikutnya (Chan, 2001, p. 39). Definisi pemuridan oleh Odgen dan Chan memiliki dua sasaran, yakni: (1) menolong seseorang untuk memiliki kedewasaan rohani dalam Yesus Kristus, sehingga ia dapat mengekspresikan imannya secara sehat dan benar; (2) setelah ia mengecap kemurahan Tuhan dalam hidupnya maka ia juga diharapkan dapat membagikan apa yang telah dialaminya itu kepada orang lain. Hal itu patut dilakukan secara terencana untuk memperlengkapi orang yang dilayani tersebut.

Setelah selesai peneguhan, pembinaan selanjutnya adalah menolong petobat baru tersebut agar tetap bertumbuh dalam imannya. Di sinilah proses pemuridan dalam kaitan dengan pendewasaan rohani dapat direalisasikan dalam diri orang percaya baru. Dalam hal ini, dapat disimak implementasi pemuridan dalam pelayanan Epafras. Hull melihat pentingnya seseorang dimuridkan untuk menjadi pengikut Yesus yang setia supaya ia benarbenar melakukan apa yang dilakukan Yesus. Itulah sebabnya warga gereja dapat menyebut Injil Kerajaan itu sebagai "Injil pemuridan." "Pemuridan"—atau hal mengikuti Yesus —adalah bagian penting dari kabar baik yang telah diberitakan-Nya (Hull, 2017, p. 10). Di sini Epafras mengambil bagian penting dalam memuridkan orang-orang Kristen di Kolose agar mereka sepenuhnya menjadi serupa dengan Yesus Kristus. Hidup seperti Yesus. Melakukan pemuridan seperti yang dilakukan Yesus. Phil Maynard menjelaskan pandangannya yang akurat tentang pentingnya pemuridan yang membawa seseorang menjadi serupa dengan Yesus. Sebab dalam tradisi alkitabiah seorang murid tidak hanya belajar tentang Yesus, tetapi menjadi seperti Yesusmenjalani hidup yang berpusat kepada Yesus Kristus (Maynard, 2015, p. 16). Tujuan dari pemuridan adalah mengembangkan seseorang agar memiliki citra hidup sama seperti Yesus Kristus. Menghidupi sifat-sifat Yesus di dalam dirinya dan menerapkannya dalam kehidupan nyata. Maynard lebih jauh menegaskan bahwa tujuan pemuridan adalah untuk melayani dalam tubuh Kristus. Itu berarti seorang murid Yesus tidak akan berhenti belajar pada level tertentu saja, tetapi ia selalu memiliki kerinduan mendalami firman Allah (Maynard, 2015, p. 17). Dengan demikian menjadi murid Yesus merupakan komitmen untuk mengikut Yesus di sepanjang hidupnya. Mereka yang telah diperlengkapi itu diharapkan ambil bagian dalam pekerjaan yang sama, pembuat murid (bdk. 2 Tim. 2:2).

\section{Memuridkan Sesuai Konteks Jemaat Kolose}

Orang-orang Kolose yang telah diubahkan Tuhan itu juga dimuridkan demi pelipatgandaan pekerja (Kol. 1:28, 29). Epafras melatih pekerja Kristus di Lembah Likhus yang rela menyerahkan diri untuk menghidupi Amanat Agung. Dari penjelasan Paulus di atas, dapat disimak bahwa pemuridan yang mereproduksi pekerja tampak jelas dalam pelayanan Epafras. Jemaat Kolose menjadi gereja yang dewasa karena faktor pemuridan yang mereproduksi. Jika tidak gereja ini akan mati. Agaknya, 40 tahun kemudian, sekitar akhir abad pertama Masehi (jemaat Kolose didirikan sekitar tahun $55 \mathrm{M}$ dan dicela sekitar tahun 90 M). Rasul Yohanes mengecam jemaat Laodikia yang suam-suam kuku karena mereka telah memadamkan semangat pemuridan di dalam gereja. Mereka telah meninggalkan warisan Epafras tentang pentingnya pemuridan di Lembah Likhus tersebut (Tenney, 1992, p. 476; Chapman, 1986, p. 167-168; Wiersbe, 2001, p. 9-11). Boleh dikatakan Epafras sebagai model dalam pemuridan yang menghasilkan buah rohani bagi kepentingan Kerajaan Allah. Menjadi gereja yang kuat di tengah-tengah masyarakat plural seyogianya mempertahankan 
pemuridan sebagai jantung pelayanannya. Jika tidak gereja akan menjadi kerdil dan mandek. Kesadaran akan hal itu telah mendorong Epafras tekun melakukan amanat pemuridan di antara konteks masyarakat Kolose yang plural dan juga sedang dihimpit oleh ajaran bidat yang merajalela di tengah-tengah jemaat. Pemuridan yang mendewasakan jemaat mengalami kepenuhan dalam Kristus sehingga mereka tahu apa yang patut diperbuat. Mereka menolak ajaran bidat dan tetap berpegang pada kebenaran Injil. Dengan demikian kontribusi Epafras sangat strategis karena menyuplai pekerja Kristus demi kelangsungan dan keberadaan kaum beriman di Lembah Likhus tersebut. Tuhan menaruh amanat pemuridan pada pundak setiap orang percaya agar mereka sadar bahwa keterlibatan mereka dalam pemuridan akan membawa pembaruan bagi setiap orang yang mengambil keputusan menjadi pengikut Yesus Kristus. Mereka bukan hanya bertobat dan menjadi warga gereja, tetapi memiliki kerinduan melipatgandakan diri bagi kepentingan Kerajaan Allah. Itulah arti sesungguhnya tentang pemuridan dalam Perjanjian Baru yakni para pengikut Yesus yang setia menghasilkan murid Kristus yang dididik untuk melipatgandaan dirinya.

Permasalahan di Kolose sangat kompleks. Wiersbe mengatakan, "Orang-orang percaya baru ini sedang menghadapi bahaya dipalingkan dari kebenaran dan mengikuti guru-guru palsu" (Wiersbe, 2001, p. 24). Sebagai jemaat di sebuah kota perniagaan, mereka menghadapi beragam konteks. Salah satunya berkaitan dengan persoalan keagamaan. Banyak agama dan guru palsu mengajarkan tentang pengejaran kepenuhan yang diusahakan melalui bertapa (2:8, 20-21), beribadah kepada malaikat (2:18), dan berpantang menyantap makanan tertentu (2:16). Mereka mungkin mencari "kepenuhan" pengetahuan batiniah. Oleh sebab itu, Paulus memberikan pemahaman tentang pentingnya kehidupan yang didasarkan pada kepenuhan di dalam Tuhan (Nggebu, 2011, p. 153).

Konteks ini menantang Epafras agar memuridkan jemaat Kolose agar memiliki keyakinan penuh hanya dalam Yesus Kristus. Merespons berita Injil itulah yang membuat mereka menjadi murid Yesus seperti yang dialami oleh para rasul. Hull mengatakan bahwa tanggapan para murid terhadap panggilan Yesus terkait dengan pemberitaan Injil Kerajaan Allah. Mereka memahami inti pesan-Nya, mengikuti Dia, dan menjadi muridNya (Hull, 2017, p. 13). Itulah yang terjadi dengan orang-orang Kolose yang merespons pemberitaan Epafras, memahami makna Injil bagi kehidupan mereka sehingga mereka menyerahkan diri kepada Kristus dan menyandang status sebagai pengikut Yesus Kristus. Mereka dimuridkan, menjadi dewasa dalam Kristus dan diperlengkapi lebih jauh agar mengambil bagian dalam menunaikan Amanat Agung. Sandra Wisantoso meyakini bahwa orang yang dimuridkan itu akan mendengar dan mengerti kehendak Yesus (Wisantoso, 2019, p. 57). Sehingga, mereka memahami tanggung jawab mereka sebagai orang yang memperoleh pengampunan dari Yesus. Selanjutnya, mereka juga akan setia mengemban amanat memuridkan orang-orang lain, sebagai wujud dalam melaksanakan Amanat Agung untuk menghadirkan Kerajaan Allah di muka bumi ini (Wisantoso, 2019, p. 63-64). Arman Barus, misalnya, mengatakan bahwa pemuridan berarti orang dibawa kepada Kristus supaya dia menjadi seperti Kristus. Lalu mereka pun jadi model untuk ditiru oleh murid berikutnya (Barus, 2005, p. 14-16). Pemuridan yang intens akan berdampak munculnya generasi pekerja Kristus dalam bidang pemuridan. Demi mewujudkan karakter Kristen di tengah masyarakat seperti yang terjadi di Kolose.

\section{Menanamkan Doktrin Kristologi Sesuai Konteks Hidup Jemaat Kolose}

Paulus dalam surat Kolose menekankan 
tentang posisi Yesus yang mulia (kepenuhan Allah) sedangkan surat Filipi menekankan tentang kerendahan Yesus yang menghamba. Sapaan kepada Yesus, "Anak-Nya yang kekasih" (1:13). Seluruh kepenuhan Allah berdiam dalam Yesus (2:9). Konteksnya bahwa Yesus menonjol dalam penciptaan, penebusan, gereja, dan kehidupan pribadi. Gelar kehormatan bagi Yesus ialah "gambar Allah yang tidak kelihatan", yang sulung yang lebih utama dari segala yang diciptakan", Ia ada terlebih dahulu dari segala sesuatu." "Segala sesuatu ada di dalam Dia", kepala jemaat", Ia yang sulung, yang pertama bangkit dari antara orang mati." "Kepada mereka Allah mau memberitahukan, betapa kaya dan mulianya rahasia itu di antara bangsa-bangsa lain, yaitu: Kristus ada di tengah-tengah kamu, Kristus yang adalah pengharapan akan kemuliaan!” (1:27). "Sebab di dalam Dialah tersembunyi segala harta hikmat dan pengetahuan" (2:3). "Sebab dalam Dialah berdiam secara jasmaniah seluruh kepenuhan ke-Allah-an" (2:9); “dan kamu telah dipenuhi di dalam Dia" (2:10a). "Dialah kepala semua pemerintah dan penguasa" (2:10b). Hikmat rohani yang dijanjikan oleh para guru palsu sudah terjawab dalam Kristus. Dialah sumber hikmat sejati. Memiliki pemahaman tentang Kristologi alkitabiah sesuai dengan pemberitaan para rasul dan juga ajaran Rasul Paulus telah berdampak dalam membangun keyakinan sehingga jemaat Kolose dapat bertahan dalam iman kepada Yesus Kristus.

Paulus mengutuk orang yang memberitakan injil yang lain (Gal. 1:9) yang berusaha menarik keluar jemaat dari komunitasnya. Menurut Wiersbe, para pengajar palsu di Kolose tidak menarik keluar orang-orang Kristen dari gereja. Mereka diharapkan tetap menjadi bagian dari tubuh Kristus dengan menerima ajaran mereka sebagai bagian dari sistem baru yang hendak diadopsikan ke dalam Kekristenan. Permintaan ini sama saja dengan menggeser iman mereka dari Kristus (Wiersbe,
2001, p. 68). Ajaran mereka sangat mengacaukan bagi jemaat. Akan tetapi Injil yang murni sangat jelas dalam surat Paulus kepada jemaat Korintus (1 Kor. 15:1-5). Bahwa Kristus telah mati untuk dosa-dosa setiap orang yang percaya kepada-Nya. Kristus telah dibangkitkan sesuai dengan Kitab Suci. Kristus yang bangkit itulah yang memelihara jemaat Tuhan, baik di Korintus maupun di Kolose sehingga tetap utuh di dalam Dia. Wiersbe yakin bahwa jemaat Kolose telah dibangun di atas Kristus, dasar yang teguh, maka mereka bertekun dalam iman dan tidak ada yang dapat menggeser mereka dari Kristus (Wiersbe, 2001, p. 56). Pada prinsipnya Injil berkuasa memelihara jemaat di Kolose sehingga mereka berdiri teguh pada fondasi yang kokoh. Talbert mengatakan bahwa doktrin Kristen diajarkan dengan metode pembelajaran yang tepat dalam pemuridan telah menghasilkan warga gereja yang dewasa dalam wawasan teologis (Talbert, 2007, p. 178). Dalam suratnya Paulus menegaskan kepada warga Kristen di Kolose agar tetap menjadikan Yesus Kristus sebagai sumber pemenuhan jati diri mereka. Damai sejahtera Kristus diharapkan tetap memerintah di dalam hati mereka (3:15); perkataan Kristus dengan segala kekayaannya tetap diam di dalam hidup mereka (3:16).

\section{Kualitas Iman Jemaat Kolose Merupakan Buah dari Kegigihan Epafras}

Pengorbanan Epafras dalam pemuridan telah membuahkan sukacita di dalam Kerajaan Allah. Firman itu sebagai benih yang tumbuh dan hidup dalam hati manusia (Luk. 8:11). Berarti firman itu hidup (Ibr. 4:12). Firman yang ditabur itu berkuasa dan berkembang di dalam hidup setiap orang yang percaya kepada Yesus Kristus. Dalam kaitan dengan pemuridan Epafras, dapat disimak beberapa ciri khas jemaat Kolose yang dewasa rohani seperti berikut:

Pertama, kualitas dalam iman (1:4a). 
Orang-orang Kolose telah menetapkan hati mereka hanya berpaut kepada Yesus Kristus sebagai sumber kepenuhan bagi jati diri mereka. Menurut Donald Guthrie, iman senantiasa dikaitkan dengan Kristus (Guthrie, 1998, p. 663). Artinya, orang-orang percaya di Kolose telah ditebus dan menjadi milik kepunyaan Yesus Kristus. Tuhan berkarya secara nyata dalam hidup mereka: melepaskan mereka dari kuasa jahat (1:13a); memindahkan mereka ke dalam kerajaan-Nya (1:13b); dan menebus mereka (1:14a) dan mengampuni mereka (1:14b). Respons mereka terhadap Yesus mengagumkan karena ternyata mereka menolak ajaran-ajaran palsu yang hendak menarik mereka keluar dari persekutuan jemaat. Itulah sebabnya Paulus mengatakan, "Dan kamu telah dipenuhi di dalam Dia" (2:10). Mereka bertumbuh dalam pengetahuan yang benar tentang Allah (1:10); hidup mereka melimpah dengan ucapan syukur (2:7) sebagai bukti dari luapan iman. Mereka sebagai orang kudus yang memiliki terang (1:12). Merujuk pada surat-surat Paulus yang lain tergambar jelas tentang posisi orang-orang percaya di Kolose sebagai orang-orang yang berserah total kepada Yesus Kristus. Iman adalah "dasar dari segala sesuatu yang kita harapkan dan bukti dari segala sesuatu yang kita lihat" (Ibr. 11:1). Jemaat Kolose adalah umat yang memiliki iman kepada Tuhan Yesus Kristus dan yang tidak digoyahkan oleh ajaranajaran lain. Mereka juga memiliki iman oleh anugerah Allah (bdk. Rm. 12:3). Dan juga karena mereka telah bertumbuh dewasa sebagai satu aspek dari buah Roh Kudus (bdk. Gal 5:22). Iman telah mendatangkan pembenaran bagi mereka (bdk. Rm 5:1). Dengan iman mereka telah menerima Roh Kudus (bdk. Gal 3:14). Sehingga Kristus berkenan tinggal di dalam hati orang-orang yang percaya (bdk. Ef 3:17). Atau dalam konteks Kolose, Kristus diam atau memerintah di antara mereka (3:15,16). Kualitas hidup jemaat Kolose merupakan kabar baik bagi gereja di sepanjang sejarah bahwa mereka sungguh-sungguh beriman kepada Tuhan Yesus di tengah-tengah arus pluralisme dan tantangan ajaran sesat yang menggempur hidup mereka. Mereka tidak goyah dan tetap berdiri teguh di hadapan Tuhan Yesus Kristus.

Kedua, kualitas dalam kasib (1:4b). Guthrie mengatakan bahwa berbicara tentang kasih maka hal itu dikaitkan dengan saling mengasihi di antara sesama manusia (Guthrie, 1998, p. 663). Orang-orang percaya di Kolose memiliki kasih yang hidup. Ciri khas mereka yakni mengasihi semua orang kudus (1:4b); mengenal kasih karunia Allah (1:6b); mengasihi dalam Roh (1:8). Ini kekuatan yang membendung mereka dari pengaruh keduniawian. Mereka benar-benar menghidupi makna dari kasih itu yang bersumber dari kasih karunia Allah, kemudian diwujudkan dalam kasih yang nyata dengan mengasihi semua orang kudus tanpa memandang latar belakang dan kedudukan sosial sebagai sebuah tantangan pada masa itu. Menurut Wiersbe jemaat Kolose memiliki ciri khas karena mengaitkan kasih dalam hubungan dengan Roh Kudus (Wiersbe, 2001, p. 26). Roh Kudus bekerja secara nyata di dalam diri mereka agar dimampukan mengasihi semua orang kudus. Mereka "bersatu dalam kasih" (2:2). Memiliki kasih Kristus yang mengikat mereka tetap bersatu (3:14) dalam konteks sosial di antara masyarakat Kolose yang plural. Mereka bukan saja tahu tentang doktrin tetapi mereka memiliki dasar ajaran yang bersumber dari kebenaran Injil Yesus Kristus. Kualitas dari kasih mereka bersumber dari kasih Kristus yang telah membawa mereka dari kegelapan dunia masuk ke dalam terang-Nya yang ajaib.

Ketiga, kualitas dalam pengharapan (1:27). Pengharapan Kristen sebagai tema yang unik dalam Perjanjian Baru. Orang Kristen dibedakan dengan mereka yang tidak memiliki jaminan keselamatan dalam Yesus. Paulus memandang orang yang tidak memiliki 
pengharapan berarti berada di luar Kristus (Gal. 4:13) dan tidak memiliki Allah (Ef. 2:11, 12). Dengan kata lain, Tuhan berkenan hadir di tengah-tengah mereka yang berpengharapan dalam Yesus Kristus. Itu berarti Yesus telah menjadi pusat pengharapan orang-orang Kristen di Kolose. Mereka berpegang pada janji Tuhan. Hidup dalam kepastian dalam Yesus Kristus. Bahwa orang percaya akan dibangkitkan bersama dengan Dia (3:1). Hidup mereka tersembunyi di dalam Dia: "Sebab kamu telah mati dan hidupmu tersembunyi bersama dengan Kristus di dalam Allah" (3:3). Bukan filsafat atau ajaran bidat yang membuat mereka bermakna melainkan Yesus Kristus. Guru-guru palsu berusaha membingungkan umat percaya di Kolose dan menggeser mereka dari pengharapan Injil (1:23). Tetapi Paulus menegaskan bahwa pengharapan ini "disediakan" di surga bagi orang-orang percaya (1:5). Wiersbe mengatakan bahwa kata "disediakan" di surga bermakna "disimpan, disisihkan untuk seseorang” (Wiersbe, 2001, p. 27). Menarik bahwa orang-orang Kristen di Kolose memiliki tiga sifat yang menonjol yakni iman, kasih, dan pengharapan. Ketiga sifat ini diraih secara utuh hanya di dalam Yesus Kristus (bdk. Rm. 5:2-5; 1 Kor. 13:13; Gal. 5:56; 1 Tim. 1:3; 5:8; Ibr. 10:22-24). Karakter iman, kasih dan pengharapan ini bukanlah angan-angan mereka tetapi sebuah realitas dalam hidup mereka yang diraih dari hubungan yang mesra dengan Yesus Kristus. Sifat-sifat khas ini yang membuat mereka bisa bersatu menolak segala tipu-muslihat si Jahat melalui para pengajar palsu yang bergentayangan di tengah masyarakat. Jika orang Kristen bersatu maka kekuatan apa pun dari dunia ini tidak akan memisahkan mereka dari kasih Kristus. Firman Allah telah menjamin kedudukan orang-orang percaya di dalam Yesus seperti yang dikatakannya dalam Roma 8:29-30. Citra Kristen itu melekat kuat pada diri jemaat Kolose. Tri Subekti mengatakan dalam tulisannya bahwa pemuridan merupakan sebuah panggilan komitmen secara pribadi kepada Yesus (Subekti, 2019, p. 7). Jemaat Kolose berkomitmen patuh setulus hati kepada Yesus Kristus. Melihat kedewasaan rohani jemaat Kolose boleh dikatakan bahwa mereka memiliki komitmen yang teguh berdiri di atas dasar ajaran para rasul sehingga mereka tetap berdiri teguh di dalam iman dan tidak bergeser dari Injil yang telah diajarkan oleh Epafras dalam memuridkan mereka.

\section{Pemuridan Konteks Kekinian}

Berbicara tentang pemuridan, kapasitas yang mumpuni tidak hanya terlihat dalam diri Epafras tetapi juga dalam diri Timotius (2 Tim. 3:10, 11) dan Titus (Tit. 2:7, 8). Paulus mengatakan kepada mereka bahwa dirinya mengikut Yesus Kristus secara total. Dia juga menuntut mereka mengikuti komitmen yang sama untuk memberitakan Injil dan memuridkan orang-orang percaya baru dalam lingkup pelayanan mereka. Ketiga sosok ini, Epafras, Timotius dan Titus, sudah menyaksikan dengan mata kepala mereka sendiri bagaimana Paulus berkontribusi bagi pembangunan warga gereja di berbagai negeri. Sekarang Paulus menegaskan kepada mereka bahwa mereka memiliki kapasitas yang sama sebagai seorang pekerja yang menghambakan diri mereka bagi kepentingan Yesus Kristus, yakni memuridkan warga gereja yang dilayani mereka dengan penuh tanggung jawab seperti yang dihidupi oleh sang mentor mereka, Paulus. Epafras telah menunaikan tugas pelayanannya dengan teladan. Ia membawa orang-orang Kolose datang kepada Tuhan, kemudian ia meneguhkan mereka, setelah dilanjutkan dengan pemuridan. Perpaduan antara peneguhan dan pemuridan sebagai dua aspek yang saling melengkapi dalam pelayanan pribadi terhadap orang-orang yang percaya agar menjadi dewasa dalam iman kepada Tuhan Yesus Kristus.

Berkenaan dengan konsep tersebut di 
atas, pada prinsipnya pemuridan tetap menjadi salah satu pendekatan strategis dalam pelayanan Kristen di era modern ini, yakni:

Pertama, pemuridan bagi gereja. Banyak gereja telah melakukan pemuridan secara intens. Pemuridan di Covenant Evangelical Free Church di Singapura yang dimotori oleh Edmund Chan menarik karena telah memberkati banyak mitra gereja di beberapa negara Asia dengan pola pemuridan yang menggerakkan seluruh sumber daya yang dimiliki oleh gereja tersebut. Beliau telah menerapkan pola pemuridan dengan memperlengkapi para pelayan di gereja yang dipimpinnya dan diharapkan mereka juga melakukan hal serupa bagi orang lain. Pertumbuhan kerohanian dalam gerejanya berjalan pesat secara internal ataupun eksternal. Selain memberkati jemaatnya sendiri, ternyata karya besar Chan juga memberkati gereja lain di beberapa negara lain termasuk Indonesia. Dalam seminar tentang pemuridan di Bandung pada 21-22 Juli 2017 dengan tema "Back To Basics: The Heart of Dicipleship," Tony Yeo mengatakan kebutuhan mendesak pada masa kini adalah pemuridan. Sebagai salah satu pembicara utama, Yeo menegaskan, pelayanan gereja bukan dilihat dari berbagai programnya tetapi gereja diharapkan mengembangkan pemuridan secara optimal dan mendewasakan jemaat memahami panggilan mereka untuk melipatgandakan diri sehingga membawa perubahan yang nyata bagi dunia (IDMC, 2017, p. 19-25). Yeo lalu mengajukan pertanyaan kritis kepada semua peserta seminar: Murid seperti apa yang diharapkan selama ini? Mencermati paparan Yeo tersebut, menurut hemat penulis, pemuridan model Epafras sebagai salah satu jawabannya. Mengapa? Orang Kristen masa kini dapat belajar dari model pemuridan Epafras. Karena ia telah memuridkan warga gereja di Kolose yang memiliki kedewasaan rohani dalam iman, kasih dan pengharapan. Mereka memahami makna Injil, meresponsnya serta meneruskan pemuridan secara berke- lanjutan. Corak pemuridan masa kini pun diharapkan dapat membangun kedewasaan rohani warga gereja yang identik dengan orang-orang Kristen di Kolose.

Kedua, pemuridan dalam konteks keluarga. Pelayanan pemuridan oleh Epafras di Lembah Likhus itu tentu saja telah menyentuh keluarga Kristen yang bertumbuh dan dewasa dalam Tuhan. Pada prinsipnya pemuridan merupakan reproduksi rohani bagi kelanjutan pembangunan rohani dalam tubuh Kristus. Pada setiap lini dalam gereja dan komunitas Kristen dapat diterapkan pemuridan yang menumbuhkan generasi rohani. Berbicara tentang struktur pembinaan rohani atau pemuridan dapat juga dilakukan dalam struktur terkecil dalam keluarga. Tan Giok Lie dalam bukunya Generasi ke Generasi (2017) memaparkan tentang pentingnya pemuridan di kalangan orang tua terutama sang ayah. Alasannya karena sang ayah berperan sebagai gembala dalam keluarga. Sehingga, kedudukan itu penting untuk dimuridkan menjadi dewasa dalam Yesus Kristus. Sang ayah dapat menjadi model yakni pemberi teladan bagi anakanaknya (Lie, 2017, p. 184-185). Proses meneladani tentu saja dapat berlangsung dengan sengaja melalui kehidupan keseharian yang berdampak pada perubahan karakter. Dalam pemuridan, proses merekam atau mengikuti pola tertentu yang diperagakan oleh orang tua sebagai gembala bagi keluarga juga sebagai mentor rohani yang dapat diandalkan dalam mendewasakan generasi berikutnya di dalam dunia modern ini.

Ketiga, pemuridan digalakekan oleh parachurch. Pemuridan yang dilakukan oleh Epafras tentu saja sebuah konsep yang memiliki relevansi bagi pelayanan pemuridan masa kini, terutama di dunia kampus. Diharapkan bahwa pemuridan bukan hanya dilaksanakan di gereja tetapi juga di antara para church. Para church yang dimaksud adalah lembaga pelayanan rohani yang memiliki peran strategis dalam pembangunan kerohanian bagi generasi pe- 
nerus seperti di dunia kampus. Karena dunia kampus sebagai arena kaderisasi pemimpin yang dinamis, kreatif dan berinovatif (bdk. Nainupu et al., 2020, 106-107, 111-115). Jika mereka dimenangkan bagi Kristus, kehadiran mereka akan mempengaruhi orang-orang yang ada di sekitar hidup mereka. Mereka diharapkan berperan dalam pemuridan dan pendewasaan kerohanian di dunia kampus. Andriani L. Soetoto dkk mengatakan bahwa Dorothy I. Marx telah meninggalkan warisan yang sangat berarti bagi banyak orang yang dilayaninya berupa nilai-nilai kehidupan, pengabdian, kasih, kemurahan, panggilan dan pelayanan (Soetoto et al., 2013, p. 7-10). Itu dikatakannya sesuai fakta bahwa pengaruh Dorothy I. Marx dalam melayani secara pribadi bagi sejumlah mahasiswa Kristen di Institut Teknologi Bandung dan di berbagai kampus sekolah tinggi teologi. Para mahasiswa yang dilayani oleh Marx secara pribadi telah mengalami hidup baru dalam Kristus dan menerapkan pola hidup yang dewasa dalam iman mereka. Hal serupa juga dikemukakan oleh Ita Siregar dalam buku Semua adalah Kemuliaan-Nya (Siregar, 2012, p. 47-65). Siregar memaparkan tentang perjalanan iman Badu Situmorang yang mengalami hidup baru di kampus ITB pada tahun 1968 dan kemudian mendedikasikan hidupnya untuk pemuridan di kampus ITB yang telah memuridkan banyak teman-temannya dan mahasiswa generasi berikutnya. Bahkan Situmorang juga masih aktif dalam pelayanan pelajar dan mahasiswa sampai saat ini (Siregar, 2012, p. 148-149).

Pembinaan rohani dalam diskusi kelompok kecil dan tatap muka sesuai dengan dinamika dunia kampus. Wiersbe melihat indikasi yang menonjol dalam pelayanan Epafras adalah memuridkan orang-orang percaya dengan pola pembinaan tatap muka yang meliputi proses belajar secara langsung yakni mendengar, mengamati dan melakukan (Wiersbe, 2001, p. 25). Di antara pembimbing dan murid yang dilayani terjalin hubungan yang interdependensi seperti yang dikemukakan oleh Yuliati dan Yemima (2019, p. 3738). Pola pemuridan yang tatap muka akan terjadi interaksi yang riil yang memberi efek yang langsung dalam kehidupan keseharian mereka. Demikian juga pandangan LeRoy Eims dalam bukunya Seni Pemuridan Yang Hilang sangatlah tepat. Beliau mengatakan bahwa orang yang dimuridkan sebenarnya mereka sendirilah yang akan memetik manfaatnya bagi diri mereka sendiri, bukan sang pembimbing (Eims, 2010, p. 29). Orang-orang yang dibimbing itu akan meraih manfaat langsung dari pemerlengkapan itu sendiri. Mereka bertumbuh dalam iman; memiliki keyakinan bahwa Yesus yang berdaulat atas hidup mereka; dan bersedia menyerahkan diri mereka untuk mengambil bagian dalam pelayanan pemuridan. Dalam konteks lain T. Haryono dan Daniel Fajar Panuntun juga memaparkan tentang konteks pemuridan Yesus terhadap Yohanes dan Yakobus dikaitkan dengan konteks pemuridan dan konseling bagi keterbukaan mahasiswa konseling (Haryono \& Panuntun, 2019, p 12-25). Para mahasiswa konseling memiliki peluang besar untuk membimbing kerohanian para konseli agar mengalami pertumbuhan dalam kerohanian mereka. Sehingga, jika mereka diperlengkapi dalam bidang pemuridan maka mereka dapat dipakai Allah untuk memuridkan dan mendewasakan setiap konseli bersandar penuh kepada Tuhan. Dunia kampus sebagai sarana pemerlengkapan bagi mahasiswa agar memiliki karakter yang mengasihi Tuhan dan pelayanan-Nya.

Keempat, pemuridan di kalangan siswa.

Dalam beberapa tahun terakhir ini pelayanan pemuridan terhadap murid-murid Kristen di persekutuan Listen, SMAN 3 Bandung telah memperlihatkan kemajuan yang berarti. Allah turut bekerja dalam pelipatgandaan pekerja yang mengambil bagian dalam melayani generasi berikutnya. Beberapa pekerja yang tumbuh dari kalangan para siswa atau alumni 
sendiri merupakan buah dari perjuangan kolaborasi antara guru dan tim mentor rohani yang aktif memperlengkapi atau mementori para siswa Kristen itu dengan memakai modul Pola Pemuridan (3 Jilid) yang diterbitkan oleh Para Navigator (Navigator, 2017, p. 5-53). Setiap minggu kelompok kecil itu dimentori oleh salah satu anggota tim mentor sebagai pengarah mendiskusikan materi tersebut secara berkesinambungan yang diakhiri dengan mencatat beberapa simpulan praktis sebagai penerapan. Ketekunan belajar bersama dalam kelompok pemuridan demi pertumbuhan iman mereka. Pada pertemuan berikunya mereka diberi kesempatan untuk menyaksikan apa saja yang telah terjadi sebagai bahan evaluasi. Mereka antusias dalam kelompok sharing tentang kemajuan atau kendala yang dihadapi. Pada prinsipnya mereka saling membangun dalam kebersamaan tentang kerohanian mereka sendiri.

Setelah beberapa semester menjalani pemuridan, muncul murid-murid yang haus dan memiliki kerinduan diperlengkapi. Ciri murid seperti itu membutuhkan tindak lanjut oleh mentor untuk disiapkan menjadi pekerja melalui program pemerlengkapan, seminar terbatas dan pribadi ke pribadi. Selanjutnya, mereka mulai aktif mementori kelompok kecil bagi adik-adik kelas mereka. Terlihat mereka merasa bebas berdiskusi dan berbagi tentang kehidupan bersama dan saling mendoakan satu sama lainnya sesuai dengan kebutuhan dunia keremajaan mereka. Itu terjadi karena tingginya tingkat saling percaya di antara mereka yang telah menyatukan mereka di dalam Yesus Kristus. Tidak ada suatu halangan pun yang membuat mereka menutupi sesuatu yang menghambat iman mereka. Mereka saling berbagi untuk memajukan iman dan pertumbuhan rohani di antara sesamanya menjadi realistis sesuai dengan konteks kehidupan generasi milenial. Agung Gunawan mengemukakan bahwa orang yang dimuridkan itu juga diperlengkapi agar memiliki kedewasaan rohani yang ditunjukkan dengan kemampuan untuk tetap berharap dan berserah kepada Tuhan (Gunawan, 2017, p. 10). Di sisi lain Tenibemas juga mengatakan bahwa andil gereja dalam pemberitaan Injil masih relevan untuk menyampaikan berita pengampunan dosa bagi manusia sebelum kedatangan Yesus yang keduakalinya (Tenibemas, 2019, p. 35). Atmosfir abad ke-21 ini menantang setiap warga gereja untuk melihat pemuridan sebagai sari pati dari keberadaan dan kelangsungan kaum beriman kepada Yesus Kristus di bumi pertiwi ini. Itu berarti orang-orang yang memperoleh pembimbingan secara rohani memiliki kesempatan yang besar dalam pengembangan dan memperlengkapi dirinya demi ikut ambil bagian dalam pembangunan manusia rohani pada generasinya, seperti kontribusi Epafras dalam pemuridan di Kolose dapat dijadikan rujukan bagi implementasi pemuridan dalam konteks kehidupan bergereja pada masa kini.

\section{KESIMPULAN}

Berdasarkan penelitian tersebut di atas, penulis menyimpulkan bahwa Epafras telah berperan secara tepat dalam mendewasakan warga gereja di Kolose. Bahwa pemuridan sebagai wadah pembelajaran yang efektif bagi warga gereja dalam mendalami firman Allah demi pertumbuhan rohani mereka. Kedewasaan rohani warga gereja bertujuan untuk memantapkan langkah iman mereka dalam mengiring Yesus sehingga mereka tetap berdiri teguh dan hidup dalam kepenuhan Kristus serta mampu menangkal setiap ajaran yang sesat yang muncul di dalam gereja. Itulah sebab orang-orang percaya yang telah dimuridkan itu didapati setia menjalankan imannya hanya berfokus kepada Yesus Kristus. Pemuridan sebagai tempat mengubahkan dan medewasakan iman umat agar berjalan dalam Yesus Kristus dan siap menunaikan Amanat Agung-Nya. Dimuridkan untuk berbuah bagi Kerajaan Allah. Maka pemuridan dalam kon- 
teks masa kini pun tetap relevan sebagai arena pendewasaan iman murid Kristus sejati di era modern ini agar tetap setia dalam iman kepada

\section{DAFTAR RUJUKAN}

Barus, A. (2005). Pemuridan sebagai Misi Gereja: Studi Matius 28: 16-20. Jurnal Amanat Agung, 2.

Bird, M. F. (2009). Colossians and Philemon (ebook). The Lutt erworth Press.

Chan, E. (2008). Built To Last (A. Tan (ed.)). Covenant Evangelical Church.

Chapman, A. (1986). Pengantar Perjanjian Baru. Kalam Hidup.

Drane, J. (2006). Memahami Perjanjian Baru. Gunung Mulia.

Eims, L. (2010). Seni Pemuridan yang Hilang. Lembaga Literatur Baptis.

Gunawan, A. (2017). Pemuridan dan Kedewasaan Rohani. Jurnal Theologia Aletheia, 19(12), 1-17. http:// sttaletheia.ac.id/wp-content/uploads/ 2017/04/Pemuridan-dan-KedewasaanRohani.pdf

Guthrie, D. (1998). Tafsiran Alkitab Masa Kini Jilid 3. Bina Kasih/OMF.

Haryono, T., \& Panuntun, D. F. (2019). Andil Pemuridan Kontekstual Yesus Kepada Petrus Yakobus Dan Yohanes Terhadap Keterbukaan Konseling Mahasiswa Pada Masa Kini. Jurnal Gamaliel: Teologi Praktika, 1(1), 12-25. https://doi.org/ 10.38052/gamaliel.v1i1.11

Hawthorne, G. F. at. al. (1993). Dictionary of Paul and His Letters (Daniel G. Reid (ed.). InterVarsity Press.

Heath, W. S. (n.d.). Penginjilan dan Pelayanan Pribadi. Yakin.

Heath, W. S. (2016). Apalogetika dan Penginjilan (Sostenis Nggebu (ed.). Biji Sesawi.

Hull, B. (2017). The Discipleship Gospel: What Jesus Preached-We Must Follow. Tyndale House Publishers.

Hutagalung, P. (2020). Pemuridan Sebagai Mandat Misi Menurut Matius 28:18-20.
Yesus Kristus, apa pun tantangan yang dihadapinya.

Pengarah: Jurnal Teologi Kristen, 2(1), 64-76. https://doi.org/10.36270/

pengarah.v2i1.22

IDMC. (2017). Back To Basics: The Heart of Discipleship (p. 100). IMDC Bandung.

Johnson, L. T. (2012). The History of Christianity from the Diciples to the Dawn of the Reformation. The Great Courses.

Lie, T. G. (2017). Generasi ke Generasi (Ria Udriana (ed.)). Visi Press.

Maynard, P. (2015). Membership to Discipleship: Growing Maturing Disciples Who Make Disciples of Jesus Christ. Excellence in Ministry Coaching.

Nainupu, M., Tabrani, A., \& Keriapy, F. (2020). Pemuridan Sebagai Upaya Menanamkan Iman Kepada Kristus Pada Mahasiswa Stak Terpadu Pesat Salatiga. VOX DEI: Jurnal Teologi Dan Pastoral , 1(2), 104-117. https://doi.org/10.46408/vxd.v1i2.34

Navigator, T. (2017). Pola Pemuridan 3: Berjalan Bersama Kristus. NavPress.

Nggebu, S. (2011). 70 Garis Besar Khotbah Biografi Para Tokoh Alkitab (Heru Winoto (ed.)). Biji Sesawi.

Ogden, G. (2007). Discipleship Essentials. InterVarsity Press.

Siregar, I. (2012). Semua Adalab Kemuliaan-Nya: Perjalanan Hidup Badu \& Wati Situmorang (S. Badudu (ed.)). Penerbit Satu-Satu.

Soetoto, A. L., Hukom, A. M., Sumawati, C., \& Ayus, P. (2013). Dorotby I Marx: Benih yang Jatuh ke Tanah (P. Situmorang \& A. P. Kristyanto (eds.)). Yayasan Bina Kasih/ OMF.

Subekti, T. (2019). Pemuridan Misioner dalam Menyiapkan Perluasan Gereja Lokal. EPIGRAPHE: Jurnal Teologi Dan Pelayanan Kristiani, 3(2), 157. https:// doi.org/10.33991/epigraphe.v3i2.126

Surakhman, W. (1998). Pengantar Penelitian 
Ilmiah Dasar Metode Teknik (VIII). Penerbit Tarsito.

Talbert, C. (2007). Ephesians and Colossians. Baker Academic.

Tenibemas, P. (2019). Andil kita dalam misi masa kini. Pengarah: Jurnal Teologi Kristen, $1(1)$.

Tenney, M. (1992). Survei Perjanjian Baru. Gandum Mas.

Treneer, M. (2012). Mengusabakan Kemajuan Injil: Surat Kolose (S. Badudu (ed.)). NavPress.

Wiersbe, W. W. (2001). Utuh di dalam Kristus: Pendalaman Perjanjian Baru-Kolose (Y.
Riskihadi (ed.)).

Wisantoso, S. (2019). Korelasi Konsep Kerajaan Allah dan Pemuridan dalam Injil Matius bagi Pemuridan Masa Kini. Veritas: Jurnal Teologi Dan Pelayanan, 18(1), 45-67. https://doi.org/10.36421/ veritas.v18i1.323

Yuliati, Y., \& Yemima, K. (2019). Model Pemuridan Konseling Bagi Alumnus Perguruan Tinggi Lulusan Baru (Fresh Graduate) Yang Mengingkari Panggilan Pelayanan. Jurnal Gamaliel: Teologi Praktika, 1(1), 26-40. https://doi.org/ 10.38052/gamaliel.v1i1.12 